methodological deficiency in this field. Perhaps the closest we come is in the comparison of Fontan patients with 2 ventricles versus those who have undergone major surgery to achieve 2 ventricles. ${ }^{7}$ Length of follow-up is too short to make a fair comparison, but it would be surprising if there was a major divergence in survival over time.

In the wake of this major contribution, we are left with a more nuanced maxim focused on a subset of people with a Fontan circulation: A not-so-bad 2-ventricle circulation is better than a bad Fontan. For the patients in this series who underwent staged recruitment of their systemic ventricle, there was substantial mortality and ongoing morbidity in replacement of mitral valves, Ross-Konno procedures, and pacemakers. Thirty-six percent were left with important elevations of pulmonary arterial pressure and 2 were functionally 1.5 -ventricle circulations. Although it is reasoned that this will be well tolerated in the future, survival benefit compared with chronic Fontan failure or transplantation is yet to be established.

We have learned much from this experience, not the least of which is a list of key acceptable parameters for left ventricular end diastolic pressure and volume associated with successful biventricular conversion. As we move forward, we should work toward acquiring and validating data points with relevant comparators and perhaps less on the maxim of the day.

\section{References}

1. Doulamis IP, Marathe SP, Piekarski B, Beroukhim RS, Marx GR, del Nido PJ, et al. Biventricular conversion after Fontan completion: a preliminary experience. J Thorac Cardiovasc Surg. 2022;163:1211-23.

2. Kreutzer C, Vive JD, Oppido G, Kreutzer J, Gauvreau K, Freed M, et al. Twentyfive-year experience with Rastelli repair for transposition of the great arteries. $J$ Thorac Cardiovasc Surg. 2000;120:211-23.

3. d'Udekem Y, Iyengar AJ, Galati JC, Forsdick V, Weintraub RG, Wheaton GR, et al. Redefining expectations of long-term survival after the Fontan procedure. Circulation. 2014;130(11 Suppl 1):S32-8.

4. Downing TE, Allen KY, Glatz AC, Rogers LS, Ravishankar C, Rychik J, et al. Long-term survival after the Fontan operation: twenty years of experience at a single center. J Thorac Cardiovasc Surg. 2017;154:243-53.e2.

5. Rychik J, Atz AM, Celermajer DS, Deal BJ, Gatzoulis MA, Gewillig MH, et al. Evaluation and management of the child and adult with Fontan circulation: a scientific statement from the American Heart Association. Circulation. 2019;140: e234-84.

6. Marathe SP, Zannino D, Shi WY, du Plessis K, Kehr J, Perumal G, et al. Two ventricles are not better than one in the Fontan circulation: equivalent late outcomes. Ann Thorac Surg. 2019;107:852-9.

7. Sun J, Brizard C, Winlaw D, Alphonso N, d'Udekem Y, Eastaugh L, et al. Biventricular repair versus Fontan completion for patients with d- or l-transposition of the great arteries with ventricular septal defect and left ventricular outflow tract obstruction. J Thorac Cardiovasc Surg. 2019;158:1158-67.e1.

\title{
Commentary: Biventricular conversion: A decade of data delivers more debate
}

\author{
Tara Karamlou, MD, MSc
}

Doulamis and colleagues ${ }^{1}$ report a retrospective report of 23 patients who underwent biventricular conversion (BiVC)

\footnotetext{
From the Division of Pediatric Cardiac Surgery, Heart, Vascular, and Thoracic Institute, Cleveland Clinic, Cleveland, Ohio.

Disclosures: The author reported no conflicts of interest.

The Journal policy requires editors and reviewers to disclose conflicts of interest and to decline handling or reviewing manuscripts for which they may have a conflict of interest. The editors and reviewers of this article have no conflicts of interest.

Received for publication May 16, 2021; revisions received May 16, 2021; accepted for publication May 18, 2021; available ahead of print May 25, 2021.

Address for reprints: Tara Karamlou, MD, MSc, Division of Pediatric Cardiac Surgery, Heart, Vascular, and Thoracic Institute, Cleveland Clinic, 9500 Euclid Ave, M41-022A, Cleveland, OH 44195 (E-mail: karamlt@ccf.org).

J Thorac Cardiovasc Surg 2022;163:1226-7

$0022-5223 / \$ 36.00$

Copyright (c) 2021 by The American Association for Thoracic Surgery

https://doi.org/10.1016/j.jtcvs.2021.05.028
}

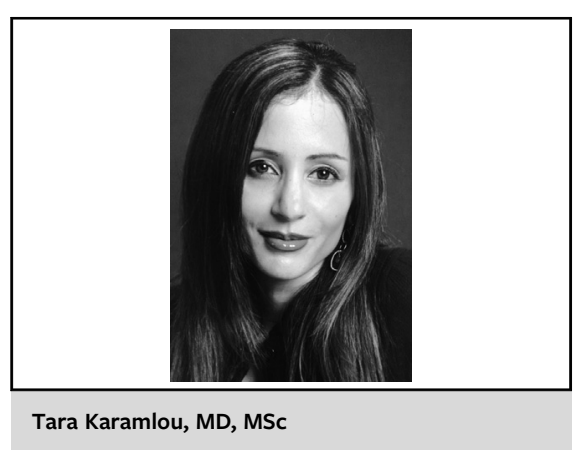

CENTRAL MESSAGE

Despite a decade of data

regarding biventricular conver-

sion, the debate about the wis-

dom of this strategy compared

with single ventricle palliation or

transplantation continues. 
following Fontan completion at their center over a 13-year period. This report builds on previously published excellent data from this center, and is an important contribution to our collective understanding regarding the selection and management of these challenging patients.

This article also provides valuable data to further inform the question articulated by Karamlou and colleagues ${ }^{2}$ : "If you force a borderline candidate down a biventricular pathway and achieve survival, what are the implications in terms of functional health status and quality of life?"

Unfortunately, there is no clear answer given the design of this study, but let's inspect the data more closely to see what can be gleaned. Of the $23 \mathrm{BiVC}$ patients included, 8 were elective conversions and the remaining 15 underwent conversion for failing Fontan physiology. Median follow-up for the entire cohort was short, at 1.1 years. The mortality rate was not insignificant: 5 patients $(22 \%)$ over the course of the study period. There was 1 $(4 \%)$ early and 4 late $(17 \%)$ deaths, with no deaths in patients who underwent elective takedown. Reintervention was required in $13 \%$, including multiple valve replacements and a Ross procedure. Almost half required recatheterization for reintervention on outflow tracts, pulmonary arteries, valves, septal defects, and coronary arteries. What about other metrics of the health of the biventricular circulation? Thirty-six percent of patients had some degree of right ventricular systolic dysfunction with right ventricular pressures $>2 / 3$ systemic pressure and the median left ventricular (LV) end-diastolic pressure in the cohort was $15 \mathrm{~mm} \mathrm{Hg}$, which might disqualify him/her from transplantation.

A premise of this therapy is that $\mathrm{BiVC}$ is superior to continuing single ventricle palliation. I recognize that the majority of the included patients were failing single ventricle circulations and therefore delineating a sufficiently sized control group is difficult. Ideally, the authors would report longitudinal outcomes in a matched cohort of group of less symptomatic patients with ongoing single ventricle palliation in the face of similar hemodynamic or physiologic issues. These data would be critical to ascertain whether the comparatively higher mortality and reintervention rates among BiVC are justified. Moreover, heart transplantation outcomes, which are comparably excellent and may be preferable in certain circumstances, could be presented to provide additional balance to the conversation.

The group from Boston has been a leader in defining an approach to BiVC. One major knowledge gap in this arena is patient selection, which is critical not only for centers that undertake BiVC, but perhaps also even more important data to elucidate for physicians and centers considering referring patients for BiVC. To this end, I would have liked additional clarity provided on this issue by Doulamis and colleagues, ${ }^{1}$ or at least the development of a defined protocol that could be prospectively investigated either as a single-center initiative or as a multicenter study. That only patients who eventuated in a successful BiVC were included in the present report is problematic because this obviates the ability to learn from failures of staged recruitment. Further, additional data about cadence and selection for staging would have been highly relevant given that staging toward anticipatory BiVC is advocated by this group. Our group has also found value in a preemptive staged approach (preferably at younger ages) in our experience with the ventricular switch, in which the borderline morphologic left ventricle is recruited as a subpulmonary ventricle. ${ }^{3}$ These caveats notwithstanding, Doulamis and colleagues ${ }^{1}$ provide some thoughtful criteria that can be leveraged in decision making: a preference toward a staged approach in those whose $\mathrm{LV}$ end-diastolic and LV end-systolic volumes are $<62.5 \mathrm{~mL} / \mathrm{m}^{2}$ and $17.5 \mathrm{~mL} / \mathrm{m}^{2}$, respectively, $\mathrm{LV}$ end-diastolic volume $>30 \mathrm{~mL} / \mathrm{m}^{2}$ considered adequate in the absence of endocardial fibroelastosis, LV end-diastolic volume $>45 \mathrm{~mL} / \mathrm{m}^{2}$ considered adequate in the presence of endocardial fibroelastosis.

Since the first report by Emami and colleagues in 2012 describing $\mathrm{BiVC},{ }^{4}$ we have all learned a tremendous amount from the courage and innovation of this group. I cannot help but be a bit deflated that after nearly 10 years, the summative inference from this present study reads, "At present it is unclear if this treatment strategy is superior to conventional single ventricle palliation or preferable to transplantation in failing Fontan patients."

\section{References}

1. Doulamis IP, Marathe SP, Piekarski B, Berouhkim RS, Marx GR, del Nido PJ, et al. Biventricular conversion after Fontan completion: a preliminary experience. J Thorac Cardiovasc Surg. 2022;163:1211-23.

2. Karamlou T, Poynter JA, Walters HL, Rhodes J, Bondarenko I, Pasquali SK, et al Long-term functional health status and exercise test variables for patients with pulmonary atresia with intact ventricular septum. J Thorac Cardiovasc Surg. 2013;154:2-5.

3. Najm HK, Karamlou T, Ahmad M, Hassan S, Yaman M, Stewart R, et al. Biventricular conversion in unseptatable hearts: "Ventricular Switch". Semin Thorac Cardiovasc Surg. 2021;33:172-80.

4. Emani SM, McElhinney DB, Tworetzky W, Myers PO, Schroeder B, Zurakowski D, et al. Staged left ventricular recruitment after single-ventricle palliation in patients with borderline left heart hypoplasia. J Am Coll Cardiol. 2012;60: 1966-74. 